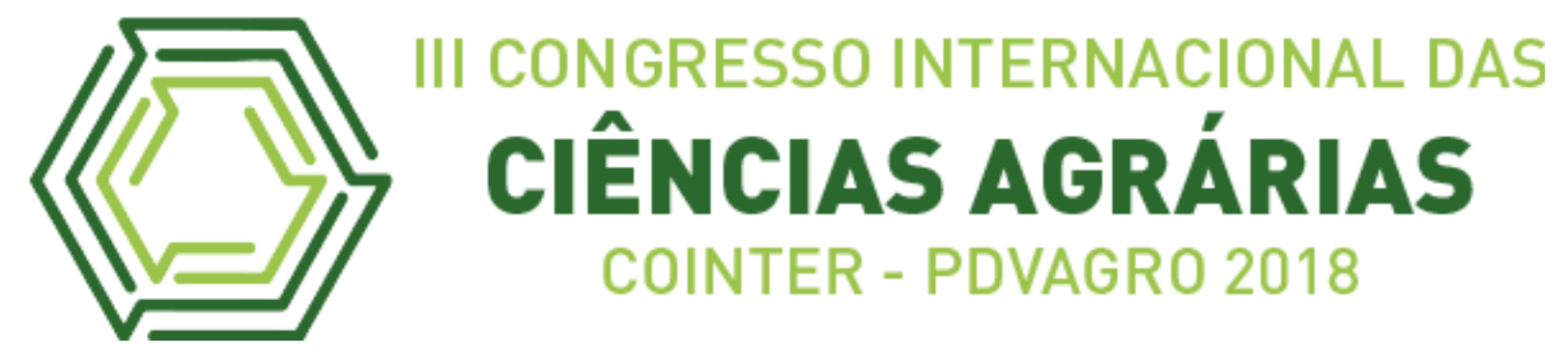

\title{
SINTOMATOLOGIA DE DEFICIENCIAS NUTRICIONAIS EM PLANTAS DE CUPUAÇUZEIRO (Theobroma grandiflorum)
}

\section{SYMPTOMATOLOGY OF NUTRITIONAL DEFICIENCIES IN CUPUAÇUZEAN PLANTS (Theobroma grandiflorum)}

\author{
Apresentação: Pôster
}

\begin{abstract}
Gabriela Mourão de Almeida ${ }^{1}$; Nayane Jaqueline Costa Maia ${ }^{2}$; Thayane Leonel Alves ${ }^{3}$; Whesley Thiago dos Santos Lobato ${ }^{4}$; Ismael de Jesus Matos Viégas ${ }^{5}$

DOI: https://doi.org/10.31692/2526-7701.IIICOINTERPDVAGRO.2018.00663
\end{abstract}

\section{Introdução}

O cupuaçuzeiro é uma fruteira da ordem das Malvales pertencente à família Malvaceae. É uma espécie frutífera arbórea nativa da região amazônica, que vem se destacando em cultivos manejados desde a década de 1970 (SANTANA, 2014). O cupuaçu se destaca atualmente como uma das frutas mais comercialmente explorada na região amazônica, tendo grandes possibilidades de participação na lista das frutas tropicais de excelente valor comercial. (CAVALCANTE et al., 2005)

Segundo a Sedap/PA (2017), o Estado do Pará tem a maior área plantada de cupuaçuzeiros no País, 12 mil hectares, onde o município de Tomé Açu desponta como o maior produtor, seguido por Moju, Acará e Bujaru, responsáveis por $71 \%$ da produção paraense. Muito disso graças ao trabalho que a Embrapa Amazônia Oriental tem realizado, que é o melhoramento genético dessa espécie e tem obtido variedades com características que garantem, ao mesmo tempo, ótima capacidade de produção de frutos e boa resistência à vassoura-de-bruxa, doença que causa redução de $70 \%$ da produção de cupuaçu no Estado do Pará (ALVES, 2012). Sendo assim o objetivo deste trabalho foi detectar a sintomatologia de plantas de cupuaçu progênie 61 na omissão de nitrogênio, fosforo e potássio

\section{Fundamentação Teórica}

\footnotetext{
1 Mestranda em Ciência do solo, Universidade Estadual Paulista Júlio Mesquita Filho; E-mail: gabrielamouraodealmeida@gmail.com

${ }^{2}$ Mestranda em Ciência do solo, Universidade Estadual Paulista Júlio Mesquita Filho; E-mail: nayane.maia1@gmail.com

${ }^{3}$ Mestranda em Ciência do solo, Universidade Estadual Paulista Júlio Mesquita Filho; E-mail: thayaneleonel@ @otmail.com

${ }^{4}$ Dicente do curso de agronomia, UFRA - Capitão Poço, E-mail: whesleylobatospfc@ gmail.com

${ }^{5}$ Docente do curso de agronomia, UFRA - Capanema, E-mail: matosviegas@ hotmail.com
} 
A progênie 61 é proveniente do cruzamento do clone 220 e 228 e produz em média 17,8 frutos por planta/safra que totalizam o peso de $34,9 \mathrm{~kg}$. Cada fruto apresenta peso médio de 2.086,2 $\mathrm{g}$, sendo 740,6 $\mathrm{g}$ de polpa. Os frutos desta progênie apresentam o comprimento médio de 262,8 mm e diâmetro de 131,4 mm com em média 32,8 sementes por fruto. Estes dados foram obtidos através das médias encontradas nas primeiras sete safras (ALVES, 2017).

A nutrição de plantas via adubação mineral é considerado um fator importante em seu desenvolvimento e no aumento de produção. Assim sendo, o fornecimento adequado e balanceado de nutrientes é essencial para favorecer ganhos significativos de produção (MENEGHETTE et al., 2017)

Os nutrientes apresentam diversas funções nos vegetais e a sua deficiência causa uma série de sintomas característicos para cada elemento, os quais são externados por sintomas típicos (SILVA et al, 2011).

\section{Metodologia}

O experimento foi conduzido em casa de vegetação da Embrapa Amazônia Oriental localizada na cidade de Belém no estado do Pará, com altitude de $10 \mathrm{~m}$. O clima da região, segundo a classificação de Köppen, é equatorial Af, com temperatura média anual de $26{ }^{\circ} \mathrm{C}$, pluviosidade média anual de três mil milímetros e umidade relativa do ar em torno de $90 \%$ (BASTOS, 1972; PEREIRA et al., 2017)

Foram utilizadas sementes de cupuaçuzeiro da progênie 61 desenvolvida pela Embrapa Amazônia Oriental, estas foram semeadas em sementeiras que continham como substrato terra preta e serragem curtida. Após estas germinarem e atingirem o ponto de palito elas foram transplantados para sacos de polietileno com dimensões de 35 x $18 \mathrm{~cm}$ x 0,20 mm pl com capacidade de $5 \mathrm{~kg}$, tendo por substrato a TFSA (terra fina seca ao ar) de Latossolo Amarelo distrófico coletado na sede da Embrapa Amazônia Oriental.

O delineamento experimental foi o inteiramente casualizado (DIC), contendo cinco tratamentos sendo estes: completo (todos os nutrientes), omissão de nitrogênio (-N), omissão de fósforo (-P), omissão de potássio (-K) e a testemunha (sem aplicação de nutriente).

Após 45 dias de transplatio foi realizado a aplicação da adubação mineral nos vasos, esta foi realizada de acordo com cada tratamento e com a técnica do elemento faltante, as seguintes doses e fontes: 
Tabela 2: Doses aplicadas nos tratamentos e suas respectivas fontes.

\begin{tabular}{ccc} 
Nutriente & Dose & Fonte \\
\hline $\mathbf{N}$ & $100 \mathrm{mg} \mathrm{kg-}^{1}$ de solo & Uréia \\
\hline $\mathbf{P}$ & $50 \mathrm{mg} \mathrm{kg-}^{1}$ de solo & Fosfato monossódico \\
\hline $\mathbf{K}$ & $90 \mathrm{mg} \mathrm{kg-}^{1}$ de solo & Cloreto de potássio
\end{tabular}

Ao final de 7 meses de experimento foi realizado análise sintomatológica visual dos tratamentos.

\section{Resultados e Discussões}

$\mathrm{Na}$ figura 1 nota-se que as folhas mais afetadas foram as que sofreram omissão de nitrogênio, assim como reduziu o desenvolvimento da altura da planta (Figura 2) e da raiz (Figura 3), quando comparado com a planta e a raiz do tratamento completo. Segundo Malavolta et al. (1997), essa deficiência nutricional causada pelo nitrogênio se deve a insuficiência desse elemento na planta, se deslocando das folhas e órgãos mais velhos para os mais novos, consequentemente, os sintomas aparecem inicialmente nas folhas velhas, com uma coloração verde clara, característico de uma menor produção de clorofila na folha.

Figura 1: Folhas de cupuaçuzeiro progênie 61 com sintomas de deficiências de nutrientes $(-\mathrm{N},-\mathrm{P},-\mathrm{K})$ em comparação com folha do tratamento completo $(\mathrm{C})$ e testemunha $(\mathrm{T})$.

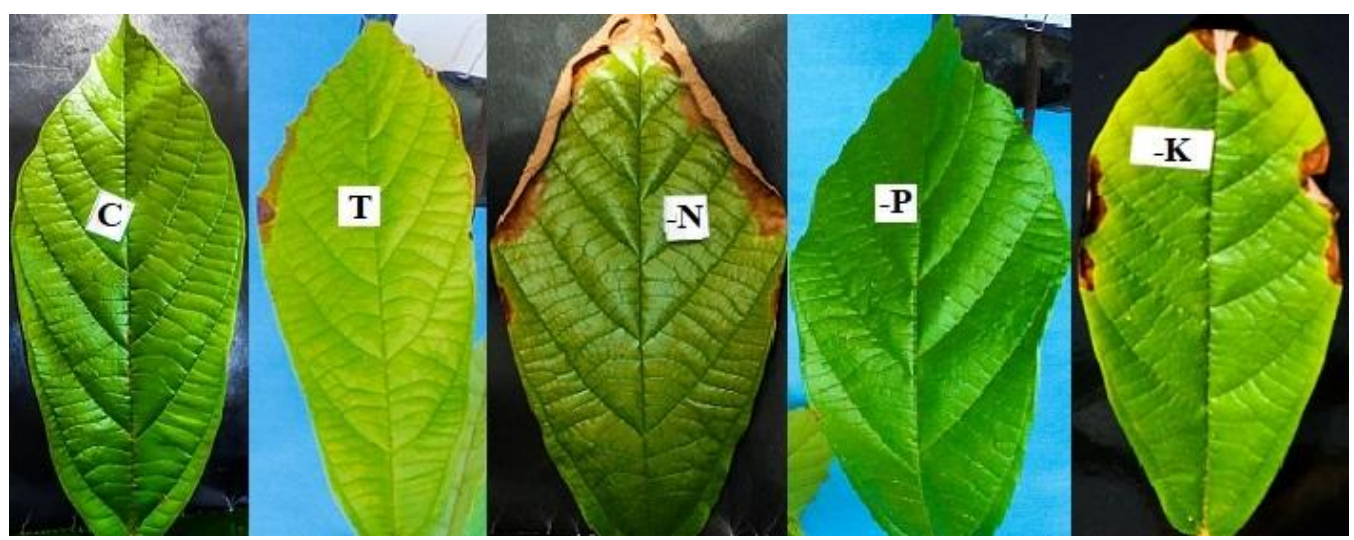

Ainda na figura 1 que as folhas de cupuaçu apresentaram sintomas bem característicos da deficiência de fósforo, que é a coloração verde escura e na figura 2 observa-se que a omissão deste nutriente reduziu a altura da planta, quando comparado com o tratamento completo, assim como nas raízes. De acordo Taiz e Zeiger (2013), assim como pode ocorrer 
na deficiência de nitrogênio, algumas espécies sob deficiência de $\mathrm{P}$ podem produzir antocianinas em excesso, conferindo às folhas coloração levemente arroxeada ou verde escura. Isso ocorre porque a deficiência de fósforo provoca a inibição da síntese de carboidratos, aumentando assim os teores de açúcares, fazendo com que estimule a síntese de antocianina (BERGMANN, 1992; MARSCHNER, 1995).

Figura 2: Plantas de cupuaçuzeiro progênie 61 com sintomas de deficiências de nutrientes (-N, -P, -K) em comparação com folha e plantula do tratamento completo $(\mathrm{C})$ e testemunha $(\mathrm{T})$.

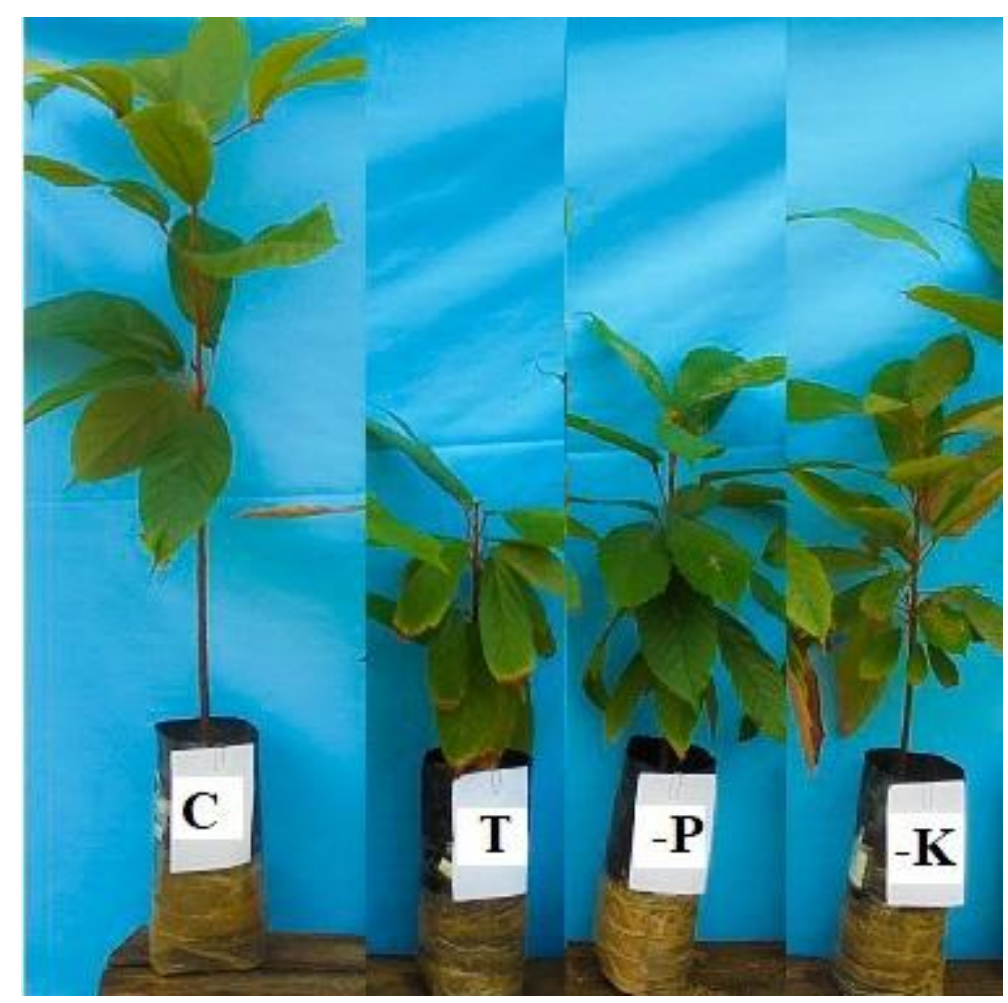

As plantas que receberam solução nutritiva com omissão de potássio mostraram um amarelecimento seguido de necrose nos bordas das folhas (Figura 1) e também crescimento reduzido (Figura 2), assim como as suas raízes (Figura 3). Raij, 1991 e Silveira et al., (2000) descreveram sintomas semelhantes, onde as folhas inicialmente apresentavam clorose e pontos necróticos das folhas mais velhas, cuja progressão ocorre das bordas em direção ao centro, junto a isso ocorre a redução da emissão de raízes novas. De acordo com Calmak (2005), o potássio é o cátion mais abundante no tecido das plantas, possuindo diversas funções fisiológicas, dentre elas: elongação celular, resistência estomática e influência na taxa fotossintética. $\mathrm{O}$ mesmo autor cita que há evidências de que a produção de espécies reativas 
de oxigênio nos cloroplastos é intensificada sob baixo suprimento de potássio, ocasionando clorose e necrose nas folhas.

Figura 3: Raízes de plantas de cupuaçuzeiro progênie 61 com sintomas de deficiências de nutrientes (-N, -P, -K) em comparação com folha e planta do tratamento completo (C) e testemunha (T) .

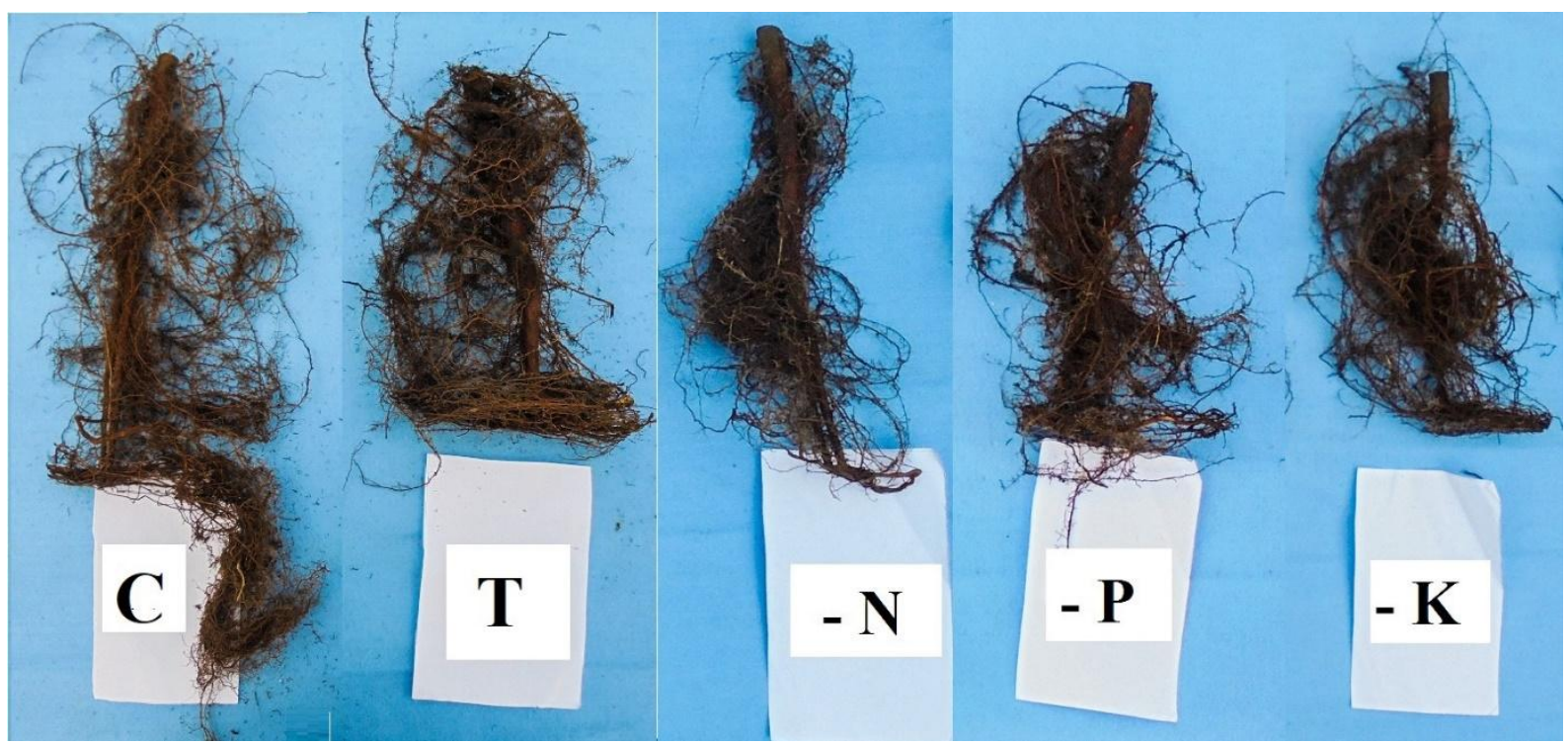

\section{Conclusões}

O conteúdo apresentado suporta a conclusão de que as plantas de cupuaçu progênie 61 são susceptíveis a deficiência desses nutrientes, e a deficiência destes reduz drasticamente as características biométricas destas plantas. Todas as omissões se mostraram prejudiciais a cultura e apresentaram a sintomatologia esperada.

\section{Referências}

ALVES, R. M. Implantação de um pomar de cupuaçuzeiro com a cultivar BRS Carimbó. Brasília, DF: Embrapa, 2012. 40 p. il. Color. 2012

ALVES, R. M. Progenie 61 [mensagem pessoal]. Mensagem recebida por <gabrielamouraodealmeida@gmail.com > em 24 janeiro de 2018

BASTOS, T. X. O estado atual do conhecimento das condições climáticas da Amazônia brasileira. In: ZONEAMENTO Agrícola da Amazônia. Belém, PA: IPEAN, 1972. p. 68-122. (IPEAN. Boletim técnico, 54).

BERGMANN, W. Nutritional disorders of plants. New York: Gustav Fischer, 1992. 741p.

CALMAK, I. Protection of plants from detrimental effects of environmental stress factors. In: Potássio na agricultura brasileira. Anais: Simpósio sobre Potássio na agricultura brasileira. Piracicaba: Associação Brasileira para pesquisa da potassa e do fosfato, 2005, p. 261-279 
MALAVOLTA, E. Avaliação do estado nutricional das plantas. Princípios e aplicações. 2. ed. Piracicaba: POTAFOS, 1997. 319p.

MARSCHNER, H. Mineral Nutrition of higher plants. 2. ed. San Diego: Academic Press, 1995. $889 \mathrm{p}$

MENEGHETTE, H. H. A.; LAZARINI, E.; BOSSOLANI, J. W.; PARRA, L. F.; HAYASHI, F. K. Doses de Fósforo e Potássio em Plantas de Amendoim na Presença e Ausência de Adubação Foliar. Brazilian Journal of Biosystems Engineering, v. 11, p. 125-134, 2017, p. 126

PEREIRA, L. G.; RODRIGUES, C. F. A.; MONTEIRO, A. R. Composição florística e estrutura da floresta secundária em um perímetro urbano, Belém-Pa. Anais: $21^{\circ}$ Seminário de Iniciação Científica da Embrapa Amazônia Oriental, 2017.

RAIJ, B. V. Fertilidade do solo e adubação. Ed. Ceres/Potafos, Piracicaba, São Paulo, Brasil, 1991, 343 p.

SANTANA, A. C. Mercado Cadeia produtiva e Desenvolvimento Rural na Amazônia. Belém: Universidade Federal Rural da Amzônia, 2014.

SEDAP PARÁ. Secretaria do Estado de Desenvolvimento Agropecuário e da Pesca. Estatística. Disponível em: <http://www.sedap.pa.gov.br/agricultura.php>. Acesso em: 28 out. 2018,

SILVA, G. F.; FONTES, P. C. R.; LIMA, L. P. F.; ARAÚJO, T. A.; SILVA, L. F. Aspectos morfoanatômicos de plantas de pepino (Cucumis sativus L.) sob omissão de nutrientes. Revista Verde, v.6, n.2, p.13-20, 2011.

SILVEIRA, R.L.V.A. et al. Avaliação do estado nutricional do Eucalyptus: Diagnose visual, foliar e suas interpretações. In: GONÇALVES, J.L.M.; BENEDETTI, V. (Eds.) Nutrição e fertilização florestal. Piracicaba: IPEF, 2000. p.79-104.

TAIZ, L.; ZEIGER, E. Fisiologia vegetal. 5. ed. Porto Alegre: Artmed, 2013. 918 p. 